\title{
ESTUDOS ULTRAESTRUTURAIS DE LINFÓCITOS, POLIMORFONUCLEARES E FAGÓCITOS DE PACIENTES COM DOENÇA DE DUCHENNE
}

\author{
GUILBERTO MINGUETTI - MARA A. D. PIANOVSKI KATO * \\ ROBIN M. HOFMEISTER ***
}

RESUMO - Os autores estudaram por microscopia eletrônica células mononucleares e granulócitos obtidos do sangue de 10 pacientes com distrofia muscular de Duchenne. Embora vários estudos tenham demonstrado alterações bioquímicas e imunológìcas nessas células do sangue, não foram encontradas alteraçōes ultraestruturais neste estudo.

\section{Citrastructure of Iymphocytes, polymorphonuclears and phagocytes of patients with muscular dystrophy.}

SUMMARY - The authors have carried out an electron microscopy study of mononuclear cells and granulocytes obtained from 10 patients with Duchenne muscular dystrophy. Although several studies have demonstrated biochemical and immunolorical defects in these blood cells. no ultrastructural abnormalities were found in the present work.

A distrofia muscular progressiva de Duchenne tem sido alvo de profundas investigações desde os primeiros casos descritos por esse autor em 1861: inicialmente, por biópsias para avaliação das fibras musculares esqueléticas; depois, por outras análises, como enzimáticas, eletroneuromiográficas e bioquímicas. Nos últimos anos, grande ênfase tem sido dada ao estudo dos vasos sanguineos, nervos periféricos $15,17 \mathrm{e}$, principalmente, das membranas celulares $8,14, \mathrm{com}$ conseqüente avaliação da atuaçāo do sódio, potássio e cálcio em relaçăo a elas. Com a atençăo dos investigadores voltada para as membranas de maneira geral, observa-se serem as plaquetas 17, hemácias $3,6,9,11,13,16,19$ e leucócitos 12 excelentes meios de estudo e avaliação das alterações das membranas celulares, dada a possibilidade de se manipular laboratorialmente estas células.

Estimulados por estes estudos e, principalmente, pelas alterações observadas no fenômeno do "capping" (termo utilizado em estudos de imunofluorescência para indicar o agrupamento polarizado de complexos antigeno-anticorpo que ocorre na superfície de linfócitos tipo B e $T$ sob certas condiçōes estabelecidas laboratorialmente) presentes na doença de Duchenne $\mathbf{1 2}$, os autores se propuseram a realizar o presente trabalho, na expectativa de que alterações ultraestruturais leucocitárias pudessem acompanhar as alterações bioquímicas e imunológicas mencionadas. Não obstante isso, Minguetti e Mair 10 , apontam a existência de fagócitos em intensa atividade fagocitica envolvendo miotubos (Fig. 9) de um feto de 9 semanas de vida intra-uterina, provavelmente acometido pela doença de Duchenne. Os fagócitos observados naquele caso apresentavam pares de grandes inclusões citoplasmáticas (Fig. 8), sendo uma clara e, a outra, escura. A presença do material destas inclusões fazia-se dentro dos próprios

Trabalho realizado na Disciplina de Neurologia do Departamento de Clínica Médica e Centro de Microscopia Eletrônica da Universidade Federal do Paraná (UFPR): * Professor Adjunto de Neurologia; ** Responsável pelo Serviço de Hematopediatria do Hospital de Clínicas da UFPR; *** Professor Adjunto, Centro de Microcospia Eletronica. 
miotubos em fagocitose. Desta forma, parte da presente investigação foi dedicada ao estudo dos fagócitos na expectativa da identificação de alterações ultraestruturass não mencionadas pela literatura que trata do assunto $1,4,5$.

\section{MATERIAL E MÉTODOS}

O material é proveniente de 10 pacientes do Hospital de Clínicas da UFPR, com duença de Duchenne. Suas idades variavam de 5 a 10 anos e o diagnóstico de certeza baseou-se na história familiar, achados enzimáticos, eletromiográficos e histopatologia muscular. Para avaliação dos leucócitos, foram retirados de eada paciente cerca de $20 \mathrm{ml}$ de sangue e levados imediatamente para separaçâo dos tipos específicos.

Os polimorfonucleares (PMN) foram obtidos segundo a técnica descrita por Bèyum (2) constituindo-se na separaçäo inicial dos mononucleares por gradiente de densidade com ficoil-hypaque $(\mathrm{d}=1077)$ e, posteriormente, na separação dos PMN por sedimentação em solução de dextrana; a suspensão final de células foi ajustada a uma concentração de $\mathbf{2 , 5}$ x $107 \mathrm{PMN} / \mathrm{ml}$ em solução tampão-fosfato. Para obtenção dos fagócitos, partículas de zymosan (Saccaromyces cerevisae) foram opsonizadas mediante incubação de $0,5 \mathrm{mg}$ com $0,5 \mathrm{ml}$ de pool de soro fresco humano durante 30 minutos a $37 \circ \mathrm{C}$; em seguida, elas foram lavadas e ressuspensas em 10ml de solução fosfato tamponada (PBS); 100 microlitros da suspensão de PMN foram, então, adicionados a $50_{\mu}$ da suspensão de partículas de zymosan; o volume foi completado para $0,5 \mathrm{ml}$ com PBS e levado a incubaçāo durante vinte minutos, a $37 \circ \mathrm{C}$; a seguir, o processo foi interrompido por centrifugação à tempcratura ambiente (300g) por 10 minutos. Os sedimentos de todas as células brancas obtidas foram fixados com glutaraldeido frio a $4 \%$ tamponado com cacodilato a $0,15 \mathrm{M}$; após duas horas de fixaçāo, o materíal foi lavado em solução de tampão cacodilato $0,15 \mathrm{M}+0,2 \mathrm{~g} \mathrm{NaCl}$ durante 15 minutos; pós-fixaçăo foi realizada $\mathrm{m}$ tetróxido de ósmio a $2 \%$ em tampão cacodilato $0,30 \mathrm{M}$ durante 30 minutos; em seguida, foi feita lavagem com solução tampão cacodilato $0,15 \mathrm{M}+0,2 \mathrm{M} \mathbf{N a C l}$ durante 15 minutos após o que foi contrastado com acetato de uranila a $2 \%$ por $\mathbf{2 4}$ horas; o material foi novamente lavado em água destilada durante 5 minutos e desidratado em graus ascendentes de álcool; em seguida, foi colocado em acetona a 100\% e embebido em Polylite; seçбes ultrafinas foram obtidas com ultramicrótomo Sorval MT2B, coletadas em grades de cobre, coradas com citrato de chumbo e examinadas em microscópio eletrônico Philips EM 300 .

\section{RESULTADOS}

Linfócitos - Os linfócitos são células sanguineas geralmente de pequeno tamanho (Figs. 1, 2 e 3) se comparadas às demais cétulas brancas; à ultramicroscopia, contudo, pode-se observar linfócitos de dimensões variadas. De qualquer forma, os linfócitos apresentam relação núcleo-citoplasma bastante alta, o que se deve às grandes dimensōcs do núcleo. O envelope nuclear é bem evidente, dando ao núcleo contorno suave, com poucas reentrâncias. o nucleoplasma contém cromatina bem nitida e distribuída na periferia. A maior parte dos linfócitos não contém em seu citoplasma granulações especificas, granuiações estas características dos granulócitos. O retículo endoplasmático rugoso é pouco desenvolvido e pequenas quantidades de glicogênio e ribossomos são observadas. Aparelhos de Golgi são pouco desenvolvidos, mas mitocôndrias săo bem evidentes $€ \mathrm{~m}$ quase todos linfócitos. Variados tipos de pequenas inclusōes citoplasmáticas foram visualizados dentro do citoplasma dos linfócitos examinados; porém, em nenhuma delas foram observadas inclusões gigantes com características especificas quanto à eletrodensidade. Finalmente, o envoltório celular é nítido e acompanha pequenas expansões citoplasmáticas características dos linfócitos (Fig. 3) que parecem nāo apresentar membrana basal, mas, apenas, membrana plasmática.

Polimorfonucleares - A análise ultraestrutural dos polimorfonucleares mostra com nitidez a característica mais importante na respectiva identificaçå, as granulaçóes citoplasmáticas (Fig. 5). Estas, por si só, permitem a fácil ciferenciação dos PMN de outras células brancas. As organelas citoplasmáticas não são bem desenvolvidas: mitocôndrias ocorrem em pequeno número; ribossomos, retículo endoplasmático rugoso e aparelho de Golgi såo pouco desenvolvidos. O polimorfismo nuclear, tal qual as granulações citoplasmáticas, constitui-se em outra característica dos PMN, Na ultramicroscopia, a lobulação do núcleo é indicada pela presença de massas nucleares separadas, cada uma das quais apresenta cromatina densa de localizaçåo periférica (Figs, 4 e 5). Os envoltórios nuclear e citoplasmático sāo bem evidentes e, a exemplo dos linfócitos, também as PMN nāo apresentam membrana basal ao redor da membrana plasmática. Apesar da presenca de granulacōes citoplasmáticas 

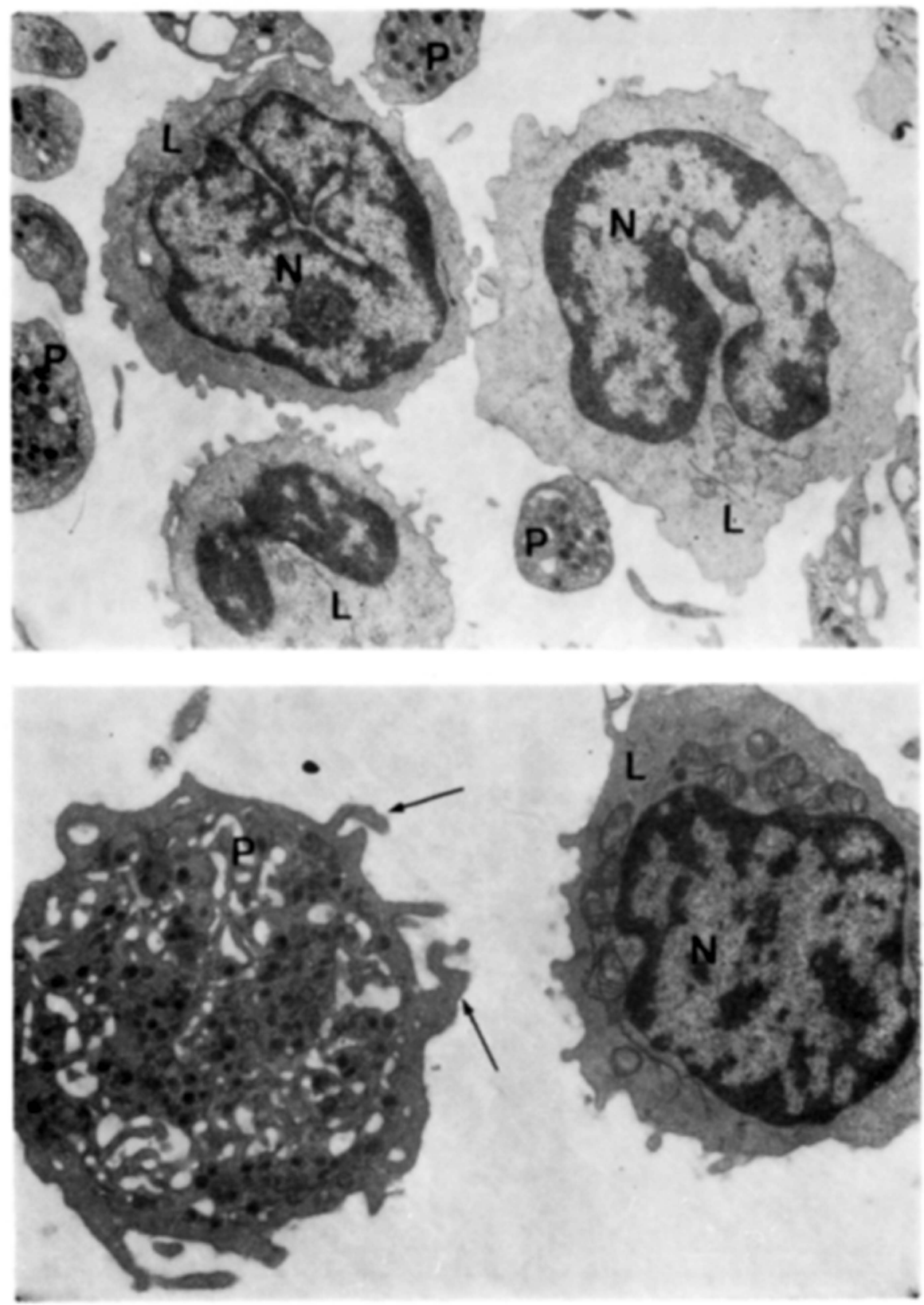

Fig. 1 (no alto) - Três linfócitos (L) rodeados por algumas plaquetas (P); observar o grande volume dos núcleos (N) em relacão ao citoplasma dos linfócitos $(\times 15000)$.

Fig. 2 (em baixo) - Lado a lado, um linfócito (L) e uma grande plaqueta (P); o núcleo (N) do linfócito é volumoso e o citoplasma apresenta quantidade regular ae mitocôndrias; a plaqueta apresenta alguns pseudópodos (setas) e, no seu interior, observa-se grande número de grânulos citoplasmáticos $(\times 11000)$. 

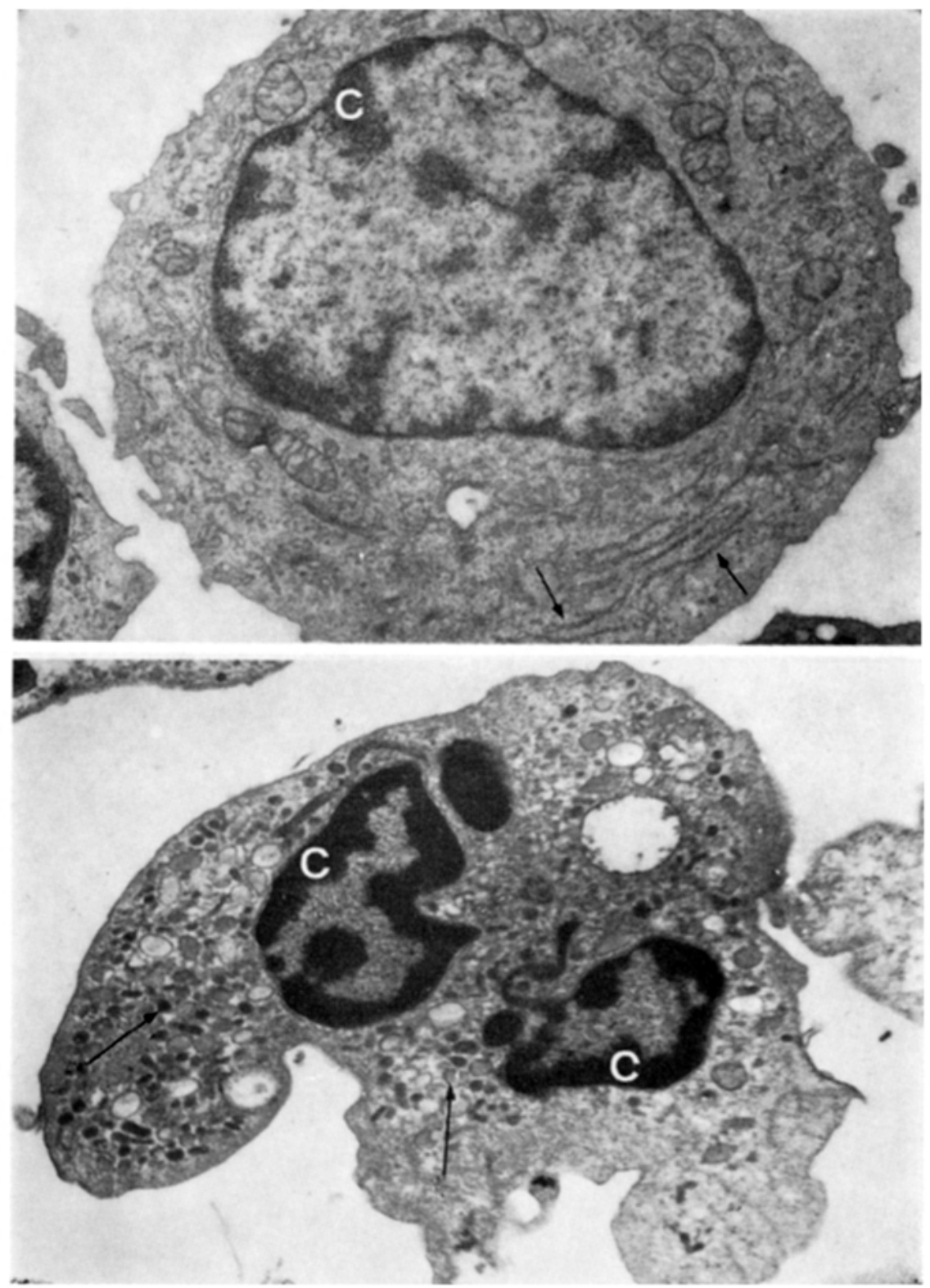

Fig. 3 (no alto) - Linfócito: seu volumoso núcleo apresenta envelope nuclear de dupla membrana no qual intercalam-se os poros; como nos casos anteriores, a cromatina (C) encontra-se dispersa na periferia do núcleo; no citoplasma observam-se poucas mitocóndrias; reticulo endoplasmático rugoso (setas) aparece em grande quantidade; ao longo do citoplasma observa-se, ainda, gnande número de partículas de ribossomos, mas não são vistas granulações citoplasmáticas canacteristicas de outras células brancas $(\times 14000)$.

Fig. 4 (em baixo) - Neutrófilo cuja lobulą̧ão do núcleo é indicada pela presenç de duas massas nucleares separadas, cada uma das quais apresenta densa cromatina (C) em sua periferia; observar que o número de mitocôndrias é pequeno $e$ o reticulo endoplasmático não é identificado em seu citoplasma; os granulos citoplasmáticos (seta) são numerosos e apresentam grande variação de forma, tamanho e eletrodensidade $(\times 12000)$. 

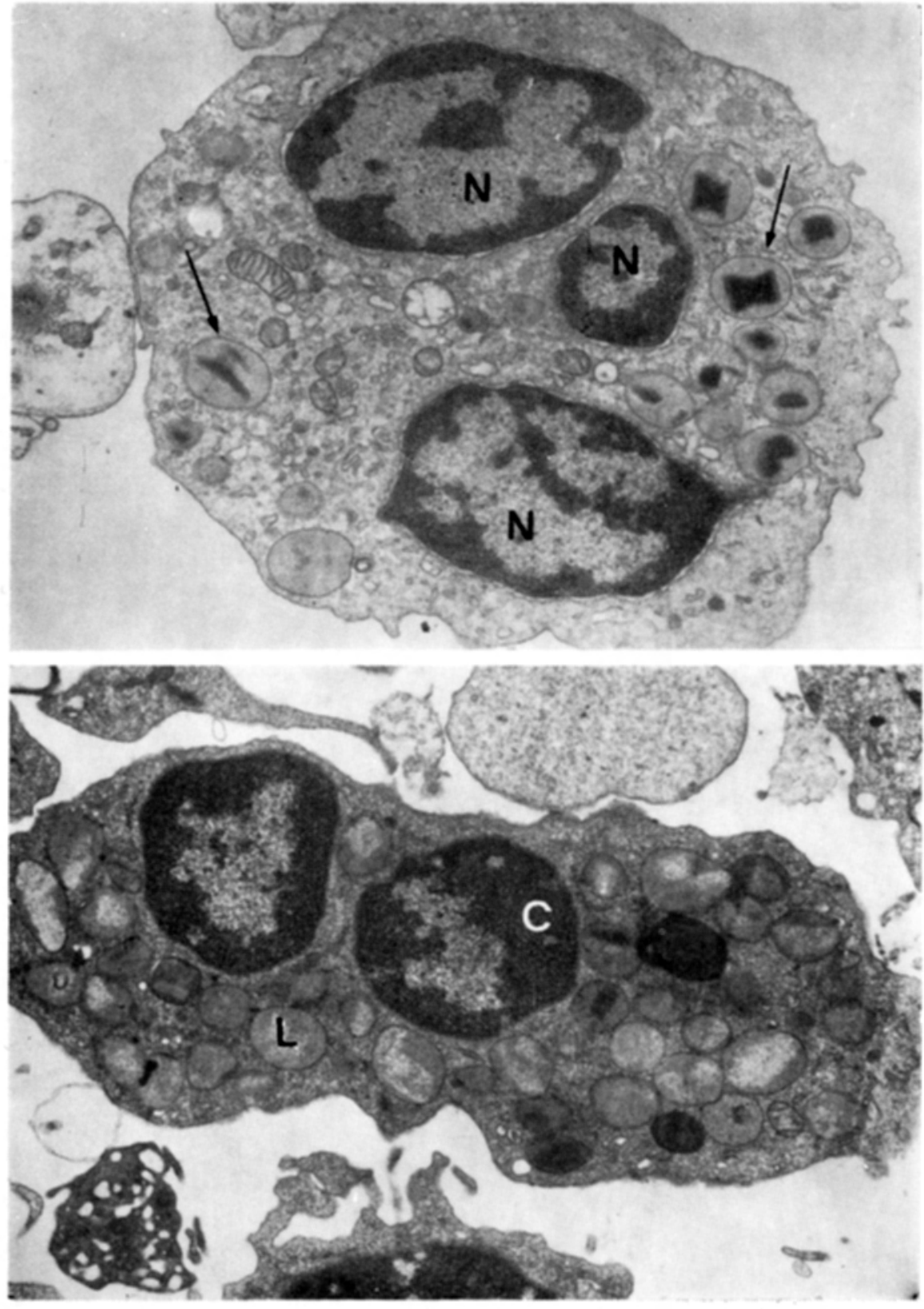

Fig. 5 (no alto) - Eosinofilo: observa-se que o corte é tangente ao núcleo em três massas nucleares (N) cuja cromatina tambem se situa na periferia; seu citoplasma apresenta pouca quantidade de ribossomos, mitocôndrias e reticulo endoplasmático; contudo, vários grânulos (seta) caracteristicos dos linfócitos são vistos; tais grânulos apresentam uma porção interna bastante eletrodensa (cristalóides) e uma porção externa pouco eletrodensa (matriz) que se senara do citoplasma por uma nitida membrana $(\times 15000)$.

Fig. 6 (em baixo) - Fagócito cujo núcleo aparece cortado em duas partes $e$ apresenta grande quantidade de cromatina (C). Seu citoplasma é quase totalmente ocupado por corpúsculos lipidicos (L); algumas granulacões contendo cristalóides em seu interior são vistas (setas) $(\times 14000)$. 


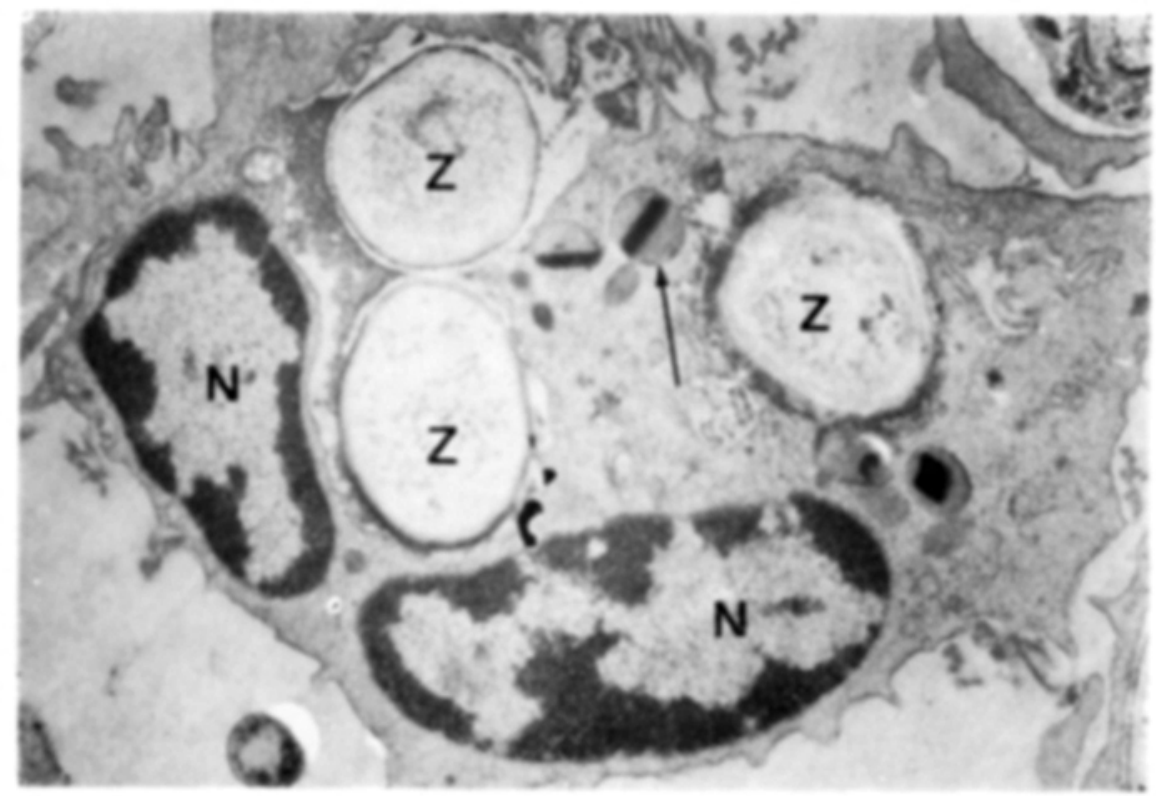

Fig. 7 - Célula com três partículas de zymosan (Z) em sen citoplasma, sofrendo processo de fagocitose; o núcleo (N) do fagócito aparece dividido em duas partes $e$, no citoplasma, alguma gramulaçóes contendo cristalódes no seu interior (setas) são observadas $(\times 12000)$.

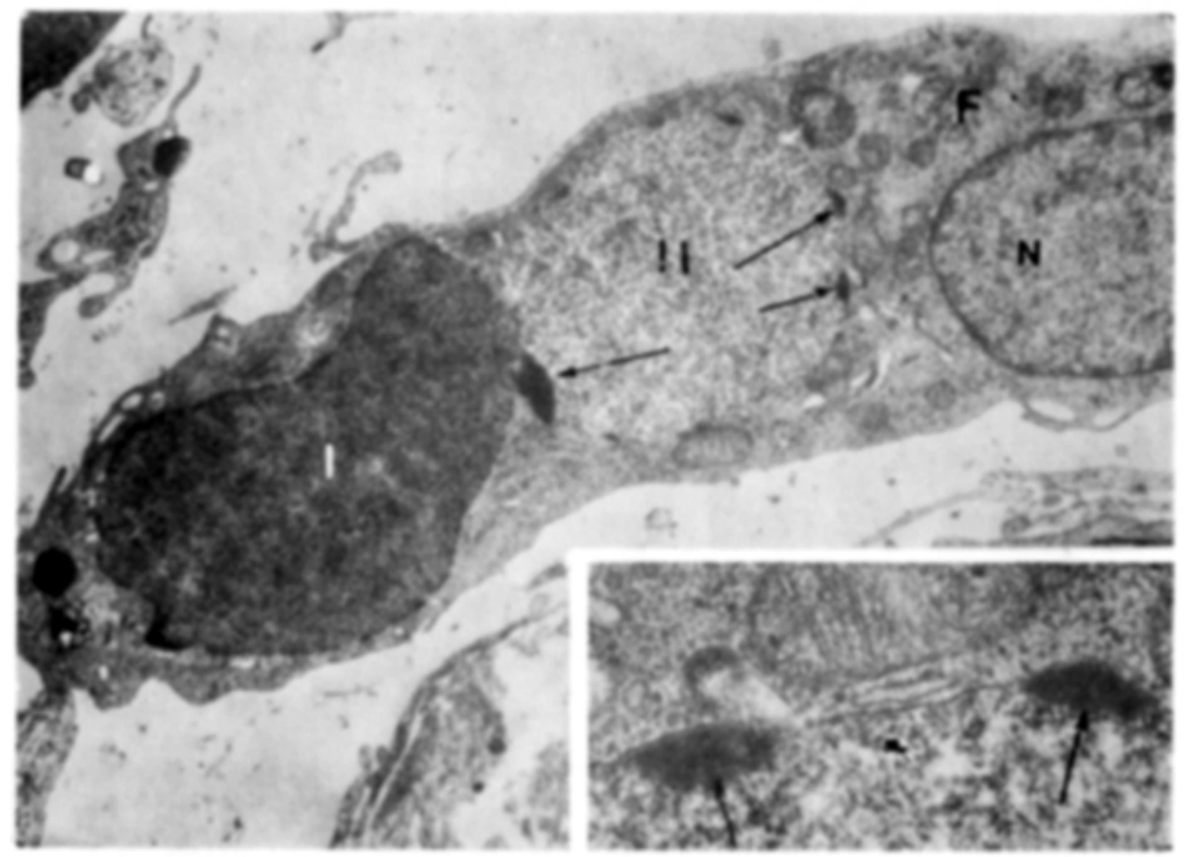

Fig. 8-Fagócito (F) com duas grandes inclusões citoplasmáticas ( $\mathrm{I}$ e II) encontrado entre miotubos de um feto provavelmente distrófico, de 9 semanas de vida intra-uterina; ambas as inclusões são limitadas por membrana; uma das inclusões é bastante eletrodensa (inclusão I); a outra (inclusão II) é clara, porém apresenta corpúsculos eletrodensos acoplados à sua membrana (setas); $N$, núcleo $(\times 10000)$; ampliação no canto inferior direito $(\times 40000)$. 


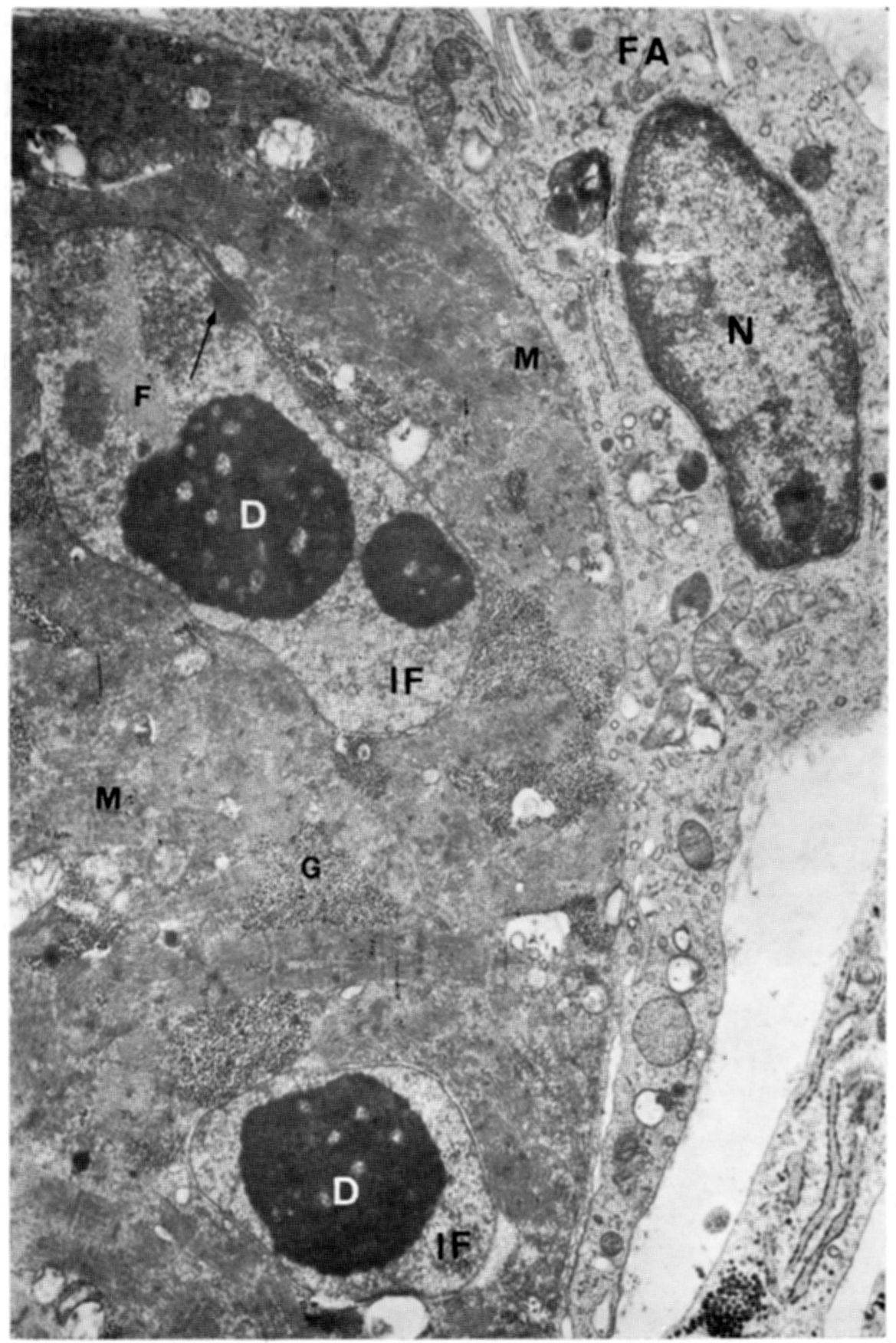

Fig. 9 - Miotubo (M) do mesmo feto mencionado na Fig. 8 sendo envolvido por fagócitos (FA); a célula muscular apresenta em seu interior infiltracões (IF) produzidas pelo fagócito e visíveis graças à orientação do corte; estas infiltrações do fagócito apresentam corpúsculos bastante eletrondensos (D) corprisculos filamentosos ( $F$ ) e na membrana que as separa da celula muscular, corpúsculos eletrondensos (seta) semelhantes àqueles observados nas inclusões claras visíveis na Fig. 8; N, núcleo; $G$, glicogênio ( $\times 12000)$. 
características dos PMN, năo foram observadas, no presente estudo; estruturas que sugerissem algum tipo patológico de inclusões citoplasmáticas.

Fagócitos - Fagócitos apresentam-se à ultramicroscopia como células de grandes dimensões e núcleos multilobulados cuja cromatina densa se distribui de forma homogênea na sua periferia (Fig. 6). A membrana plasmática é bem evidente e grande número de expansōes citoplasmáticas são observadas. Organelas citoplasmáticas (corio aparelho de Golgi, mitocôndrias e retículo endoplasmático) não são proeminentes, embora granulaçōes sejam identificadas. Embora partículas de zymosan ou mesmo plaquetas fossem constantemente observadas sofrendo processo de fagocitose (Fig. 7), também nos fagócitos não foram identificadas inclusôes gigantes procuradas nas demais células estudadas no presente trabalho.

\section{COMENTARIOS}

Teorias recentes apregoam que defeitos das membranas celulares seriam responsáveis pelas alterações observadas nas fibras musculares de pacientes com distrofia muscular tipo Duchenne. Acredita-se que esses defeitos seriam consequências do erro genético presente nesses pacientes e que as alteraçóes de membrana seriam transmitidas também a outros tipos de células do organismo doente, além das fibras musculares. Para caracterização desses defeitos, os autores têm utilizado as células do sangue por se tratarem de células de fácil aquisição e manuseio. Vários estudos apontam que as membranas de eritrócitos obtidos tanto de paciente com distrofia miotônica como daqueles com Duchenne são diferentes das membranas eritrocitárias normais. Tais alterações incluem variações quanto a forma do eritrócito, fragilidade osmótica, transporte do sódio e potássio através da membrana plasmática, alterações da absorção do cálcio, fosforilação das proteínas e fluidez da membrana, anormalidades relativas à ATPase $\mathrm{Na}^{+}$e $\mathrm{K}^{+}$e outras $3,6,9,11,13,16,19$. Com relação às células brancas, são de particular interesse os estudos relacionados aos linfócitos e, destes, o mais significativo dos últimos anos diz respeito ao trabalho de Pickard e col.12. Estes autores estudaram o "capping" em 61 pacientes com os vários tipos de distrofia muscular. Os resultados mostraram diminuiçăo importante da percentagem de células que apresentavam "capping", quando comparado com grupo controle de indivíduos normais. Foi observado, ainda, que os portadores (mães) heterozigotos de Duchenne apresentavam diminuição do número de células linfocitárias com o fenômeno de "capping" proporcionalmente igual ao número observado nos próprios doentes ocorrendo isto mesmo quando os níveis séricos das enzimas (CPK, LDH, SGOT e SGPT) estão normais. Os autores acreditam que tal fato seja decorrente de alteração da fluidez das membranas plasmáticas dos linfócitos de pacientes com distrofia muscular, pois a técnica do "capping" permite a observação da mobilidade lateral normal das proteinas das membranas no plano da superfície celular, refletindo defeito sistêmico das membranas celulares. Curiosamente, até a época da publicação do artigo de Pickard e col., a única doença que apresentava diminuição da percentagem do "capping" linfocitário era a leucemia linfocitica crônica.

O presente estudo da ultraestrutura dos linfócitos de pacientes com Duchenne, contudo, não apresentou evidências de alteraçôes da microestrutura das membranas plasmáticas destas células, sugerindo que os defeitos encontrados por outros autores devem estar relacionados exclusivamente aos aspectos bioquímicos e ou imunológicos cujas causas básicas são ainda de especulação científica.

Como foi mencionado anteriormente, outro fato que levou os autores à realização do presente trabalho foi a observação em estudo anterior 10 de grandes inclusões - uma clara e outro escura - no citoplasma de fagócitos de um feto de 9 semanas de vida intra-uterina, provavelmente com distrofia de Duchenne. Tais inclusões não foram identificadas pelo seu tamanho e cor em outras condições patológicas nas quais participam as células brancas 1,4,5. Daí porque tentou-se, no presente trabalho, por estimulos apropriados com partículas de zymosan obter-se fagócitos de pacientes com Duchenne para serem analisados. A expectativa era de que pela microcospia eletrônica tais inclusões pudessem ser normalmente identificadas no citoplasma destes fagócitos. Elas, contudo, não foram visualizadas no material examinado e, possivelmente, representam circunstância específica da fagocitose de células musculares. Apesar de tudo, os autores acreditam que estas inclusões, as quais devem ser ricas em enzimas digestivas, e as células que as albergam deveriam ser alvo de investigações mais refinadas por parte dos investigadores das doenças musculares, pois evidências delas são detectadas pela microscopia eletrônica nas células musculares sob fagocitose em qualquer fase da vida de pacientes distróficos 7. 


\section{REFERENCIAS}

1. Bessis M - Cellules du Sang Normal et Pathologique. Masson, Paris, 1972.

2. Böyum A - Isolation of mononuclear cells and granulocytes from human blood. Scand $\mathrm{J}$ Clin Lab Invest (Suppl) $97: 77,1968$.

3. Butterfield DA, Chesnut DB, Appel SH, Roses AD - Spin label study of erythrocyte mebrane fluidity in myotonic and Duchenne muscular dystrophy and congenital myotonia. Nature 263:159, 1976.

4. Carr I - The Machrophage: A Review of Ultrastructure and Function. Academic Press, London, 1973.

5. Cawley JC, Hayhoe FGJ - Ultrastructure of Haemic Cells: A Cytological Atlas of Normal and Leukaemic Blood and Bone Marrow. Saunders, London, 1973.

6. Headings VE, Anyaibe SIO, Akindele J, Onaga M - An erythrocyte membrane antigen associated with X-linked muscular dystrophy. Arch Neurol 40:300, 1983.

7. Mair WGP, Tomé FMs - Atlas of the Ultrastructure of Diseased Human Muscle. Churehill-Livingstone, Edinburgh, 1972.

8. Mawatari S, Miranda A, Rowland LP - Adenyl cyclase abnormality in Duchenne muscular dystrophy: muscle cells in culture. Neurology 26:1021, 1976.

9. Mawatari S, Igisu H, Kuroiwa $\mathbf{Y}$, Miyashino $\mathbf{S}-\mathbf{N a}++\mathbf{K}+\mathbf{A T P a s e}$ of erythrocyte membranes in Duchenne muscular dystrophy. Neurology 31:293, 1981.

10. Minguetti G, Mair WGP - Ultrastructure of developing human muscle. Biol Neonate $40: 276,1981$.

11. Moliman JE, Pleasure DE - Erythrocyte calcium transport in myotonic and fascioscapulohumeral muscular dystrophy. Neurology 34:1514, 1984.

12. Pickard NA, Gruener HD, Verril HL, Isaacs ER, Robinow M, Nance WE, Myers EC, Goldsmith B - Systemic membrane defect in the proximal muscular dystrophies. N EngI J Med 299:841, 1978.

13. Plishker GA, Gitelman HJ, Appel SH - Myotonic muscular dystrophy: altered calcium transport in erythrocytes. Science 200:323, 1978.

14. Roses AD, Herbstreith MH, Appel SH - Membrane protein kinase alteration in Duchenne muscular dystrophy. Nature 254:350, 1975.

15. Rowland LP - Pathogenesis of muscular dystrophy. Arch Neurol 33:315, 1976.

16. Sarpel G, Lubansky HJ, Danon MJ, Omachi A - Erythrocytes in muscular dystrophy: investigation with $31 \mathrm{P}$ nuclear magnetic resonance spectroscopy. Arch Neurol 38:271, 1981.

17. Walton JN - Muscular dystrophy: some recent developments in research. Isr $J$ Sci $13: 152,1977$.

18. Yaron R, Meyer S, More R, Liebergall M, Eldor A - Platelet abnormalities in muscular dystrophy. Thromb Haemosts (Stuttyart) 49:168, 1983.

19. Yoshida $M$, Ando $K$, Satoyosh1 $E$ - Abnormalities of erythrocytes in Duchenne muscular dystrophy. Ann Neurol 13:649, 1983. 